\title{
Türkiye'de Turizm Gelirleri ve Ekonomik Büyüme İlişkisinin Kamu Politikaları Doğrultusunda Değerlendirilmesi
}

Eda BALIKÇIO $\breve{G L U}$, Department of Public Finance, Faculty of Economics and Administrative Sciences, Kirikkale University, Turkey; e-mail: edabalikcioglu@kku.edu.tr

Kutay OKTAY, Department of Tourism and Hospitality Management, Faculty of Tourism, Kastamonu University, Turkey; e-mail: koktay@kastamonu.edu.tr

\section{An Assessment of the Relationship between Tourism Revenues and Economic Growth in Turkey in accordance with the Public Policy}

\begin{abstract}
The contribution of tourism that arrange country's economies is frequently discussed in the literature. Researching the economic impacts of tourism, public policies considerable effects undeniable. The aim of this paper is to investigate the causal relationship between economic growth and tourism by using quarterly data for Turkey for the period of 2003-2014. The results show that there is a co-integration between tourism and economic growth. In addition, our results for the Granger causality test indicate that there is a unidirectional causality from economic growth to tourism. At the end of this study, these relationship is evaluated in accordance with the public policy.

Keywords

Tourism Sector, Economic Growth, Public Policy, Granger Causality Analyses.

JEL Classification Codes : $\quad$ L83, 040, H30, C22.

\section{$\ddot{\mathbf{O z}}$}

Turizmin ülkelerin ekonomilerine sağladığı katkılar literatürde sıklıkla tartışılmaktadır. Turizmin ekonomik etkileri incelendiğinde kamu politikalarının önemli etkileri olduğu yadsınamamaktadır. Çalışmanın amacı Türkiye'deki ekonomik büyüme ve turizm arasındaki nedensellik ilişkisini kamu politikaları doğrultusunda incelemektir. Bu amaçla 2003Q1-2014Q2 dönemini kapsayan çeyrek verileri kullanarak turizmle ekonomik büyüme arasındaki ilişki Granger nedensellik testi ile incelenmektedir. Analiz sonucunda ekonomik büyümeden turizme doğru tek yönlü nedensellik bulunmaktadır. Çalışmanın sonucunda bu nedensellik ilişkisi kamu politikaları doğrultusunda değerlendirilmektedir.
\end{abstract}

Anahtar Sözcükler $\quad$ : Turizm Sektörü, Ekonomik Büyüme, Kamu Politikaları, Granger Nedensellik Analizi. 


\section{Giriş}

Turizm ve seyahat sektörü hizmet ekonomisi içerisinde yer alan ve Dünya Turizm Örgütü'ne göre hâlihazırda dünyanın en büyük ve gelecektede büyümeye ve istihdam yaratmaya devam edecek olan endüstrilerinden biridir. Turizm aynı zamanda ulusal ve bölgesel kalkınmada da önemli bir rol oynamaktadır ve birçok ülke için önemli bir gelir ve istihdam kaynağı olma özelliğine sahiptir. Buna rağmen dünyada ekonomi ve maliye araştırmaları içerisinde turizm halen çok fazla yer almamaktadır. Turizmin bir çok alt sektörden oluşan entegre yapısı turizm ile ilgili ekonomik ve mali verilerin hesaplanmasını ve ölçülmesini zorlaştırma ve karmaşıklaştırmaktadır (Nordin, 2003: 14-15).

Turizm döviz girdisi ve istihdam yaratma gibi özelliklerinden dolayı önemli bir sektör olarak kabul edilmektedir. Turist kabul eden ülkeler açısından en çok iki gösterge önemli görülmektedir. Bunlar turist alım sayısı ve turizm geliridir. Turizm özellikle yoğun turist alan destinasyon ülkeler açısından önemli bir ihracat kalemi olarak kabul edilmektedir. Turizm bu ülkelerde ekonomiye gelir artışı, ödemeler dengesi, istihdam ve fiziksel sermaye anlamında önemli katkılar sağlamaktadır (Lee, 2008: 89-90).

Turizm faaliyetleri yapısı gereği birçok sosyal, kültürel, ekonomik ve mali etkileri birlikte barındırmaktadır. Ekonomik ve mali etkiler genel olarak gelir yaratma, döviz girdisi sağlama, ödemeler bilançosu açıklarını kapatma, vergi gelirlerini artırma, üretimi ve istihdamı artırma olarak ifade edilebilir. Bunlara ek olarak turizm, ekonomideki diğer sektörleri de canlandırma etkisine sahiptir (Kara vd., 2012: 79).

Turizm sahip olduğu tüm bu özellikler sayesinde ekonomi içerisinde önemli bir yer tutmaktadır ve Dünya turizm gelirleri pastası büyüdükçe bu pastadan daha fazla pay almak isteyen ülkeler için turizmin önemi her geçen gün artmaktadır. Bu değerlendirmeler doğrultusunda turizmin sağladiğı gelir ile ekonomik büyümeyi desteklediğini söylemek mümkündür. Elbette bu desteğin oranı ülkeden ülkeye değişmektedir. Bu nedenle turizm bazı ülkelerin ekonomileri açısından daha da önemli hale gelmektedir.

Günümüzde bireylerin sosyo-ekonomik ve kültür düzeylerinin artması, turizm talebinin de yükselmesini beraberinde getirmektedir. Dünyada ekonomik refahın yükselmesi, ulaştırma sektörünün gelişmesi, sanayi toplumlarında ücretli izin sürelerinin uzaması, iletişim teknolojisindeki gelişmeler, yaşlı nufüsün artması, sanayileşme sonucu ortaya çıkan yeni toplumsal örgütlenme ve aile yapısındaki değişme ve teknoloji kaynaklı stres gibi faktörler turizminde gelişmeyi tetiklemektedir (Aktaş, 2010: 164; Karataş \& Babür, 2013). 
Tüm bu verilerin ışığında turizmin ekonomik büyümeye etkisine benzer olarak aynı şekilde ekonomik büyümenin de turizmin gelişmesine etki ettiğini söylemek mümkündür. Ekonomik gelişmişlik düzeyi ile bireylerin gelirlerinin artması diğer lüks mal ve hizmetlere olduğu gibi turistik hizmetlere olan talebi de yükseltmekte ve bu da turizmin gelişmesini beraberinde getirmektedir.

Doğası, coğrafi konumu, tarihi, kültürü ile büyük bir turizm potansiyele sahip olan Türkiye, son yıllarda uluslararası turizmde önemli bir marka olmayı ve 2012 yılı itibariyle turist sayısında dünya sıralamasında 6. turizm gelirlerinde ise 10. sırada yer almay1 başarmıştır. Türkiye'nin turizmde elde ettiği bu başarının ekonomik etkilerinin incelenmesinde, bu başarıları daha da ileriye götürecek politikaların geliştirilmesi açısından yarar vardır. Bu noktadan hareketle hazırlanan bu çalışmada Türkiye'de 2003-2014 yılları arasında turizm ve ekonomik büyüme arasındaki ilişkinin kamu politikaları doğrultusunda incelenmesi amaçlanmıştır.

\section{Literatür İncelemesi}

Turizmin ekonomik etkileri üzerine yapılan çalışmalar arasında en popüler olanları turizm ve ekonomik büyüme arasındaki ilişkiyi inceleyen turizm-büyüme etkisi hipotezlerdir. İhracat-büyüme etkisi hipotezinde olduğu gibi, turizm-büyüme etkisi hipotezi de turizmdeki büyümenin ekonomik büyümeyi de tetiklediğini öngörmektedir. Jackman (2012), çalışmasında, turizmin GSYİH'ya doğrudan etkisinin yanı sıra, tarım, inşaat, ulaştırma, iletişim, eğlence ve yiyecek içecek gibi diğer ekonomik sektörleri de canlandırma özelliğine sahip olduğunu vurgulamıştır.Nitekim, turizmin büyüme etkisinin turizmin ekononominin diğer sektörlerini canlandırması ile gerçekleşebileceği çeşitli yazarlar tarafindan savunulmaktadır (Marin, 1992; Oh, 2005; Kima vd., 2006).

Oh (2005) çalışmasında, ticaretle ekonomik büyüme arasındaki ilişkiyle ilgili üç teoriden söz etmektedir. Bunlar, turizm ekonomik büyüme yaratır hipotezi, ekonomik büyüme turizmi sürükler hipotezi ve karşılıklı etki hipotezidir. Bunlardan ilki kısaca turizmin ekonomik büyümeye neden olduğunu, ikincisi ekonomik büyümenin turizmi olumlu etkilediğini ve üçüncüsü ise turizm ve ekonomik büyümenin birbirini iki yönlü olumlu etkilediğini ifade etmektedir (Chen vd., 2009: 813).

Literatürde turizmin ekonomik büyüme üzerine etkileri inceleyen çalışmalar, genellikle turizm gelirleri ve ekonomik büyüme arasındaki iliş̧ki üzerinde yoğunlaşmaktadır. $\mathrm{Bu}$ çalışmaların tek bir ülkede veya karşılaştırmalı olarak bir kaç ülkede gerçekleştirildiği ve genellikle panel veri ve zaman serileri analizi kullanıldığı görülmektedir (Bahar ve Kurtuluş, 2010). 
Balaguer ve Jorda (2002), turizm ile İspanya ekonomisinin uzun dönemdeki gelişimi arasındaki ilişkiyi ele almıştır. Yine buna benzer bir çalışmada Martin ve diğerleri (2004) Latin Amerika Ülkelerinde turizm ve ekonomik gelişme arasındaki ilişkiyi panel veri analizi yöntemi ile incelemiştir. Sequeira ve Campos (2005), turizmin ekonomik büyüme üzerindeki etkisini turizmin yoğun olduğu ülkeler ve diğer ülkeleri karşılaştırarak panel veri analizi yöntemi ile incelemiştir. Ertuğrul ve diğ. (2013) çalışmalarında 1998-2011 yılları arasında Türkiye'yi sınır testiyle incelemişlerdir. Çalışmanın sonucunda Türkiye'de turizmin ekonomik büyümeye neden olduğu hipotezini savunmuşlardır.

Belloumi (2010), Turizmin Tunus'un ekonomik büyümesindeki rolünü, 19702007 yılları arasında turizm gelirleri, GSYİH ve efektif döviz kurları arasındaki ilişkiyi incelemiştir. Buna göre turizm gelirleri ve ekonomik büyüme arasında bir ilişki bulunduğu ve turizmin dolaylı yoldan GSYİH üzerine olumlu etkisi olduğu tespit edilmiştir.

Aslan'ın (2008) çalışmasında 1992-2007 dönemi arasında Türkiye'de turizm ve ekonomik büyüme ilişkisini zaman serisi yöntemiyle analiz etmiştir. Ekonomik büyüme ve turizm gelirleri arasında uzun dönemli dolaylı bir ilişkinin olduğu sonucuna ulaşmıştır. Bahar ve Kurtuluş (2010) çalışmalarında, 21 gelişmekte olan ülkeyi 1998-2005 döneminde dinamik panel veri analiziyle incelemişlerdir. Aslan (2008) çalışmasına benzer bir sonuca ulaşmıştır. Gelişmekte olan ülkelerde turizmden ekonomiye doğru tek yönlü pozitif bir ilişki bulmuşlardır.

Aktaş (2005) çalışmasında, Türkiye'nin 1980-2000 yılları arasında elde ettiği turizm gelirlerini, turist sayısı, yatak kapasitesi, seyahat acentası sayısı, tanıtıma ayrılan pay, yabancı sermaye miktarı, dolar ve mark cinsi döviz kuru değişkenleri yardımıyla zaman serileri analizine tabi tutmuştur ve çalışmanın sonucunda seyahat acentası ve turist sayısının artırılmasının ekonomik büyüme üzerinde olumlu etkiler yarattığını ifade etmişlerdir.

Gündüz ve Hatemi (2005) çalışmalarında, turizmin büyüme üzerindeki etkisini 1963-2002 yıllık IMF verileriyle ARCH modeliyle analiz etmişlerdir. Çalışmanın sonucunda turizmin büyümeye neden olduğu hipotezini desteklemişlerdir.

Türkiye'de ekonomik büyümeden turizme doğru tek yönlü nedensellik ilişkisini savunan çalışmalarda söz konusudur. Bunlardan biri, (Kızılgöl \& Erbaykal, 2008) çalışmasıdır. Çalışmada, Türkiye'deki turizm gelirleri ile ekonomik büyüme arasındaki nedensellik ilişkisi incelenmiştir. 1992-2006 dönemlerini kapsayan çalışmada, ekonomik büyümeden turizm gelirlerine doğru tek yönlü bir nedensellik ilişkisi ortaya çıkmıştır. Çalışmanın sonucu olarak turizm gelirlerini artırmak için sürdürülebilir büyümeyi yakalamak gerektiği savunulmuştur. Fayıssa ve diğ. (2008) çalışmalarında, 1995-2004 yılları arasında 42 Afrika ülkesini dinamik panel veri yöntemiyle analiz etmişlerdir. 
Çalışmanın sonucunda ekonomik büyümenin turizmi geliştirdiği sonucuna ulaşmışlar ve bunun için fiziki ve beşeri sermaye yatırımlarını artırıp, ticaret ve yabancı doğrudan yatırımları teşvik etmeye yönelik politikalar izlenmesi gerektiğini savunmuşlardır.

Değer (2006) çalışmasında,1980-2005 dönemini zaman serilerini kullanarak analiz eden çalışmada turizm gelirinin ekonomik büyümeyi artırmada çok etkili olmadığ sonucuna ulaşmışlardır. Yavuz (2006) çalışmasında da, Türkiye'de 1992-2004 dönemindeki turizm gelirindeki artışın ekonomik büyümeye etkisi araştırılmıştır. Çalışmanın sonucunda turizm gelirleri ile iktisadi büyüme arasında herhangi bir nedensellik ilişkisi bulunamamıştır. Özdemir ve Öksüzler (2006) ise çalışmalarında turizmle ekonomik büyüme arasında uzun dönemde turizmden ekonomik büyümeye doğru tek yönlü ilişki bulmuşlardır.

Katırcıoğlu (2009) çalışmasında 1960-2006 yılları arasında Türkiye'de turizm büyüme etkisi hipotezini zaman serisi analiziyle incelemiştir ve sonuçta Türkiye'de turizmle ekonomik büyüme arasında bir ilişki gözlememiştir.

\section{Veri ve Yöntem}

Çalışmada turizmle büyüme arasındaki ilişki VAR modeli ile analiz edilmiştir. VAR modelleri, dinamik ilişkileri yapısal modelleri kısıtlamadan verebilen ve bu özelliğinden dolayı zaman serileri içinde yaygın olarak kullanılan bir modeldir (Keating, 1990: 454). VAR modellerinde bağımlı değişkenlerin gecikmeli değerleri yer almakta ve bu da geleceğe yönelik tahminlerin gücünü artırmaktadır (Maddala, 1989: 329-330).

İki değişkenli bir VAR Modeli denklem 1 ve 2'de ifade edilmektedir.

$$
\begin{aligned}
& y_{t}=\sum \alpha_{i} y_{t-i}+\sum \beta_{i} x_{t-i}+\varepsilon 1 t \\
& x_{t}=\sum \alpha_{i} x_{t-i}+\sum \beta_{i} y_{t-i}+\varepsilon 2_{t}
\end{aligned}
$$

Çalışmanın temel amacı, turizmle büyüme arasında bir ilişkinin olup olmadığını test etmek ve eğer ilişki varsa, ilişkinin yönünü ortaya koymaktır. Tüm değişkenler doğal logaritmik şekildedir. Modeldeki değişkenler turizm geliri (tg) ve GSYİH (gsyih)'dır. Çalışma 2003Q1-2014Q2 dönemini kapsamakta ve zaman serisi yöntemiyle analiz edilmektedir. Çalışmadaki veriler T.C Merkez Bankası Elektronik Veri Dağıtım Sistemi ve Türkiye İstatistik Kurumu turizm veri setinden alınmıştır. Model aşağıdaki şekilde tanımlanmaktadır. 
$\ln g$ syih $=\alpha_{0}+\alpha_{1} \ln t g+\varepsilon t$

Modelde ilk olarak turizm gelirinin mevsimsel özellik gösterdiğinden dolay1 mevsimsellik özelliğini yok etmek gerekmektedir. Bu nedenle verilerin öncelikle Census X12 yöntemiyle mevsimsellik özelliği ortadan kaldırılmıştır. Daha sonra VAR (Vektör Otoregresyon) modelini uygulayabilmek için serilerin durağan olmaları gerekmektedir. Bir serinin durağan olması için ortalaması ve varyansının zaman içinde değişmemesi ve iki dönemin ortak varyansının hesaplandığı dönem yerine iki dönem arasındaki uzaklığa göre hesaplanması gerekmektedir (Gujarati, 1995: 713). Çalışmada kullanılan zaman serilerinin durağanlığını ölçmek amacıyla, Augmented Dickey-Fuller (ADF) ve Philips-Perron (PP) testleri uygulanmıştır.

\section{Analiz Sonuçları}

Tablo: 1'de yer alan ADF ve PP birim kök test sonuçları her iki seri için de, boş hipotezin \%1 anlamlılık düzeyinde 1. farklarında reddedildiğini göstermektedir. Bu duruma göre ADF ve PP birim kök testleri sonucunda seriler 1. farklarında durağandırlar. Bu noktada aralarında eş bütünleşme ilişkisi olup olmadığı analiz edilebilir.

Tablo: 1

ADF ve PP Birim Kök Test Sonuçları

\begin{tabular}{|l|l|l|l|l|}
\hline & ADF (düzey değeri) & ADF (1.fark) & PP (düzey değeri) & PP (1.fark) \\
\hline \multirow{3}{*}{ Ingsyih } & -1.8813 & $-4.2311^{*}$ & -1.5611 & $-4.1303^{*}$ \\
& Kritik Değerler & Kritik Değerler & Kritik Değerler & Kritik Değerler \\
& $\% 1(-3.59)$ & $\% 1(-3.59)$ & $\% 1(-3.58)$ & $\% 1(-3.59)$ \\
\hline \multirow{3}{*}{ Intg } & -1.0247 & $-6.7488^{*}$ & -0.5508 & $-8.4360^{*}$ \\
& Kritik Değerler & Kritik Değerler & Kritik Değerler & Kritik Değerler \\
& $\% 1(-3.58)$ & $\% 1(-3.59)$ & $\% 1(-3.58)$ & $\% 1(-3.59)$ \\
\hline
\end{tabular}

Not: *\%1 düzeyinde anlamlılı̆̆l göstermektedir.

Turizm ve ekonomik büyüme arasında uzun dönem ilişki olup olmadığını görebilmek amacıyla VAR modeli uygulanmıştır. Johansen $(1988,1991)$ ve Johansen ve Juselius (1990) çalışmalarında uygulanan VAR modeli değişkenler arasında eşbütünleşme olup olmadığına bakmaktadır. Eğer değişkenler arasında eşbütünleşme varsa uzun dönem ilişki söz konusu olmaktadır. Model için değişkenler arasında gecikme uzunluğu Akaike Bilgi kriteri (AIC), Schwarz Bayesyen Kriteri (SBC) ve Hannan-Quinn Kriterleri (HQC) dikkate alınarak bulunmuştur. Tablo: 2'de testler doğrultusunda gecikme sayısı "1" olarak belirlenmiştir. 
Tablo: 2

VAR Modeli Gecikme Uzunluğu Seçimi

\begin{tabular}{|c|c|c|c|c|c|c|}
\hline Lag & LogL & LR & FPE & AIC & SC & HQ \\
\hline $\mathbf{0}$ & 39.23118 & NA & 0.000582 & -1.772913 & -1.690167 & -1.742583 \\
\hline $\mathbf{1}$ & 163.0109 & $229.8767^{*}$ & $1.94 \mathrm{e}-06$ & -7.476711 & $-7.228472^{*}$ & $-7.385722^{*}$ \\
\hline $\mathbf{2}$ & 167.3594 & 7.661666 & $1.91 \mathrm{e}-06$ & -7.493307 & -7.079576 & -7.341658 \\
\hline $\mathbf{3}$ & 172.8400 & 9.134336 & $1.79 \mathrm{e}-06^{*}$ & $-7.563811^{*}$ & -6.984588 & -7.351503 \\
\hline $\mathbf{4}$ & 175.5131 & 4.200458 & $1.92 \mathrm{e}-06$ & -7.500622 & -6.755906 & -7.227654 \\
\hline
\end{tabular}

Tablo: 3'te eş bütünleşme testi sonuçları yer almaktadır. Eşbütünleşme testinde iki olabilirlik oranı (LR) kullanmaktadır. Bunlar iz istatistiği (trace statistics) ve maksimum öz değer istatistiğidir (max. eigen value). Bunların hipotezleri ise iz istatistiği için boş hipotez $r$, maksimum öz değer istatistiği içinse $r+1$ vektör vardır şeklindedir. Bu kapsamda VAR modeline dayalı Johansen eş bütünleşme sonuçları Tablo: 3 'te yer almaktadır.

Tablo: 3

\section{Johansen Eşbütünleşme Testi Sonuçları}

\begin{tabular}{|l|c|c|c|c|}
\hline Ho & İz İstatistiği & \%5 kritik değer & Maks. özdeğerist. & \%5 kritik değer \\
\hline Ho $=0$ & 19.55 & 19.49 & 16.88 & 14.26 \\
\hline Ho $\leq 1$ & 2.67 & 3.84 & 2.67 & 3.84 \\
\hline
\end{tabular}

Johansen eş bütünleşme analizinde iz istatistiği ve maksimum özdeğer istatistiği kritik değerden büyükse hipotezler reddedilmektedir. $\mathrm{Bu}$ doğrultuda $\% 5$ anlamlılık düzeyinde eş bütünleşmenin olmadığ 1 boş hipotezler reddedilmektedir ve kurulan modelde eş bütünleşme söz konusudur. Bu doğrultuda uzun dönemde ekonomik büyümeyle turizm gelirleri arasında uzun dönemli bir ilişki bulunmaktadır.

Tablo: 4

Granger Nedensellik Testi Sonuçları

\begin{tabular}{|l|c|c|}
\hline Nedensellik Yönü & ChiSq & Prob \\
\hline Turizm Geliri $\rightarrow \rightarrow$ Büyüme & 1.86 & 0.1729 \\
\hline Büyüme $\rightarrow \rightarrow$ Turizm Geliri & 10.66 & 0.0011 \\
\hline
\end{tabular}

Engle ve Granger (1987) ve Granger (1988) çalışmalarında iki seri arasında eşbütünleşme olduğunda ya tek yönlü ya da çift yönlü nedenselliğin olduğunu belirtmektedirler. Çalışmamızda son olarak, turizm gelirleri ve ekonomik büyüme arasında nedensellik testi sonuçları Tablo: 4'te gösterilmektedir. $\mathrm{Bu}$ sonuçlara göre, turizm gelirlerinden ekonomik büyümeye doğru bir nedensellik ortaya çıkmazken, ekonomik büyümeden turizm gelirlerine doğru tek yönlü bir nedensellik ilişkisi ortaya çıkmıştır. 
Türkiye'de bu ilişkinin yönünün değişmesi olarak son yıllarda turizm talebinin ve yeni dönem turistlerin vizyonlarının değişmesi gösterilmektedir. Son dönem turizm talebini spor turizmi, sağlık turizmi, kongre turizmi, tarihi ve kültürel turizm, gelişmiş ve güvenli ulaştırma, altyapı, üstyapı ve kurumsal hizmet, doğa turizmi ve sektör alanında vasıflı personel oluşturmaktadır (Özdemir \& Öksüzler, 2006: 113). Bu faaliyetlerin gerçekleşmesi ise büyük çapta nakdi harcamalara ihtiyaç duyulmaktadır. Buna bağlı olarak analiz sonucunda ortaya çıktığı gibi ekonomik büyüme turizmin gelişmesine neden olmaktadır.

\section{Turizm ve Ekonomik Büyüme İlişkisinin Kamu Politikaları Doğrultusunda Değerlendirilmesi}

Turizm sektörü diğer sektörlerden farklı olarak devletin uyguladığı politikalardan ve günlük gelişmelerden daha fazla etkilenmektedir. Turizm sektörünün gelişmesinde devlet desteğinin özel sektör açısından iki önemli yararı bulunmaktadır. Bunlardan ilki sermaye gereksinimi ve sermaye maliyetini azaltmasıdır. Devletin turizm sektörü üzerinde uygulayacağı politikalarda temel amaç GSYİH'yı artırmaktır (Metodijeski \& Temelkov, 2014: 236-237).

Turizm sektörü için devletin yapmış olduğu harcamalar sıklıkla altyapı (yolcu taşımaya yönelik yatırımlar, çevre düzenlemeye yönelik harcamalar, hijyen ve sağlık amaçlı yapılan harcamalar, sosyalleşmeyi sağlamak amacıyla yapılan aktivite harcamaları, yol, terminal, havaalanı, liman yapmak, turistlere yönelik ücretsiz gezi uygulamaları, parklara, müzelere bedava giriş gibi), turizmi geliştirmeye ve büyütmeye yönelik reklamlar, ulusal turist alanlarında pazarlama ve reklam çalışmaları olarak yapılmaktadır (Koncul, 2007: 8991).

Tablo: 5'te 2003-2013 yılları arasında sektörel sabit sermaye yatırımları gösterilmektedir. Kamu sektörünün turizm için yaptığı yatırımların \%1'i bile geçmediği ancak özel sektörün yatırımlarının ağırlıkta olduğu gözlenmektedir. Ancak analiz sonucunda ortaya çıkan duruma göre son dönemde turizm sektörünün kalkınması için devletin de turizme yönelik sabit sermaye yatırımlarını artırması gerekmektedir. 
Tablo: 5

2003-2013 Dönemi Sektörel Sabit Sermaye Yatırımları/GSYİH (Cari Fiyatlarla)

\begin{tabular}{|l|c|c|c|c|c|c|c|c|c|c|c|}
\hline & $\mathbf{2 0 0 3}$ & $\mathbf{2 0 0 4}$ & $\mathbf{2 0 0 5}$ & $\mathbf{2 0 0 6}$ & $\mathbf{2 0 0 7}$ & $\mathbf{2 0 0 8}$ & $\mathbf{2 0 0 9}$ & $\mathbf{2 0 1 0}$ & $\mathbf{2 0 1 1}$ & $\mathbf{2 0 1 2}$ & $\mathbf{2 0 1 3}$ \\
\hline Kamu sektörü & & & & & & & & & & & \\
\hline Tarım & 7,9 & 9,2 & 8,0 & 7,0 & 8,9 & 8,6 & 12,8 & 9,9 & 9,8 & 10,5 & 10,3 \\
\hline Madencilik & 1,0 & 1,5 & 1,5 & 2,0 & 2,0 & 1,7 & 2,1 & 1,9 & 2,3 & 2,5 & 2,7 \\
\hline İmalat & 2,6 & 2,7 & 1,7 & 2,1 & 1,0 & 0,9 & 1,1 & 0,8 & 0,7 & 1,1 & 1,3 \\
\hline Enerji & 16,7 & 13,4 & 12,3 & 10,2 & 10,3 & 9,2 & 9,5 & 6,5 & 5,7 & 5,8 & 6,7 \\
\hline Ulaştırma & 27,2 & 33,7 & 34,4 & 33,4 & 29,1 & 37,7 & 29,9 & 43,7 & 41,4 & 39,0 & 31,9 \\
\hline Turizm & $\mathbf{0 , 8}$ & $\mathbf{0 , 7}$ & $\mathbf{0 , 5}$ & $\mathbf{0 , 4}$ & $\mathbf{0 , 4}$ & $\mathbf{0 , 4}$ & $\mathbf{0 , 3}$ & $\mathbf{0 , 5}$ & $\mathbf{0 , 6}$ & $\mathbf{0 , 7}$ & $\mathbf{0 , 7}$ \\
\hline Konut & 1,0 & 1,0 & 1,7 & 1,4 & 1,6 & 1,5 & 1,5 & 1,5 & 1,7 & 1,5 & 2,0 \\
\hline Eğitim & 14,2 & 13,5 & 11,5 & 11,4 & 12,2 & 9,9 & 12,4 & 10,4 & 12,2 & 13,9 & 15,3 \\
\hline Sağlık & 5,7 & 5,0 & 5,8 & 5,9 & 6,7 & 5,6 & 6,9 & 4,8 & 5,0 & 5,1 & 5,7 \\
\hline Diğer Hizmetler & 23,0 & 19,4 & 22,7 & 26,3 & 27,8 & 24,6 & 23,4 & 20,1 & 20,5 & 19,9 & 23,4 \\
\hline Özel Sektör & & & & & & & & & & & \\
\hline Tarım & 2,4 & 3,9 & 3,2 & 3,6 & 2,6 & 1,8 & 1,0 & 2,3 & 3,3 & 2,8 & 2,7 \\
\hline Madencilik & 2,0 & 1,9 & 1,8 & 1,6 & 1,5 & 1,5 & 1,5 & 1,5 & 1,5 & 1,6 & 1,6 \\
\hline İmalat & 36,3 & 41,4 & 44,4 & 46,0 & 46,1 & 45,2 & 42,8 & 41,4 & 42,2 & 40,4 & 40,8 \\
\hline Enerji & 2,8 & 1,6 & 2,1 & 2,8 & 3,3 & 3,9 & 7,2 & 5,5 & 4,0 & 6,2 & 6,3 \\
\hline Ulaştırma & 15,9 & 19,0 & 19,3 & 17,4 & 16,9 & 18,3 & 21,6 & 19,1 & 19,9 & 19,6 & 19,4 \\
\hline Turizm & $\mathbf{7 , 5}$ & $\mathbf{7 , 0}$ & $\mathbf{7 , 4}$ & $\mathbf{6 , 7}$ & $\mathbf{5 , 1}$ & $\mathbf{5 , 8}$ & $\mathbf{6 , 0}$ & $\mathbf{6 , 9}$ & $\mathbf{6 , 2}$ & $\mathbf{6 , 7}$ & $\mathbf{6 , 6}$ \\
\hline Konut & 21,7 & 15,3 & 11,4 & 12,0 & 14,5 & 12,6 & 10,4 & 14,8 & 14,4 & 13,8 & 13,4 \\
\hline Eğitim & 1,5 & 1,2 & 1,1 & 1,0 & 1,0 & 1,3 & 0,8 & 1,3 & 2,2 & 2,4 & 2,6 \\
\hline Sağlık & 3,5 & 3,7 & 4,6 & 4,5 & 4,6 & 4,9 & 3,3 & 2,9 & 2,4 & 2,2 & 2,4 \\
\hline Diğer Hizmetler & 6,4 & 5,1 & 4,7 & 4,3 & 4,4 & 4,7 & 5,4 & 4,4 & 4,0 & 4,2 & 4,1 \\
\hline
\end{tabular}

Kaynak: Kalkınma Bakanlı̆̆l, Ekonomik ve Sosyal Göstergeler, 15.07.2015.

Türkiye'de turizme yönelik uygulanan kamu politikalarının ağırlıklı olarak turizme yönelik yatırım, istihdam ve vergi teşvikleri ve bu teşviklerin de ağırlıklı olarak vergisel teşvikler olduğu görülmektedir. Bunları özetlemek gerekirse, KDV'de hizmet ihracatı istisnası, turizm firmaları açısından deniz ve hava taşıma araçları ile liman ve hava meydanlarında yapılan hizmetler istisnası, gayrimenkul satışlarında KDV istisnası, Türkiye'de ikamet etmeyen yolculara yapılan teslimlerden doğan KDV istisnası, gelir ve kurumlar vergisi istisnaları, damga vergisi ve harçlarla ilgili teşviklerdir (Tezcan ve diğ., 2008: 831-840). Ayrıca KOSGEB kapsamında sağlanan destek ve hizmetler, yatırımlarda devlet yardımları hakkında Bakanlar Kurulu kararı kapsamında uygulanan teşvik ve destekler, 2634 Sayılı Turizmi Teşvik Kanunu ile sağlanan teşvikler, 1319 Sayılı Emlak Vergisi Kanunu'nda yer alan muafiyetler, Türkiye İhracat Kredi Bankası (EXIMBANK) tarafından sağlanan kredi imkânları, yabancı sermaye yatırımlarının teşviki, yurtdışı turizm fuarlarına katılım desteğidir (Kültür ve turizm Bak, 2012: 2-56). 


\section{Sonuç ve Öneriler}

Dünyada ve Türkiye'de her geçen yıl istikrarlı olarak büyüyen bir sektör olması ve ekonomik faaliyetler içerisindeki önemi itibariyle turizm, iktisat ve maliye alanında yapılan çalışmaların inceleme konusu olmaya artarak devam etmektedir. Turizmin ülkelerin ekonomilerine sağladığı katkıların ne düzeyde olduğunun belirlenmesi, bu alanda çalışmalar yapan araştırmacılar tarafindan en fazla merak edilen ve incelenen konuların başında gelmektedir. Turizmin ekonomik büyüme etkisi üzerine yapılan analizlere yoğunlaşan bu çalışmalarda, özellikle gelişmekte olan ülkelerde turizmin ekonomik büyümeye olan katkısı ölçülmekte ve çıkan sonuçlara göre turizmin ekonomik büyüme etkisi hipotezi kabul veya reddedilmektedir. Buna göre bu konuda yapılan çalışmaların genellikle turizmin ekonomik büyümeye yaptığı katkıların genellikle ön plana çıkarıldı̆̆ını söylemek mümkündür.

Turizmin ekonomik büyüme üzerine olan etkilerinin yoğun olarak dikkate alındığı turizm ve ekonomik büyüme arasındaki ilişkiyi diğer bir bakış açısıyla incelediğimizde, çoğu zaman ekonomik büyümenin de turizmi tetiklediği görüşünü ortaya atmak mümkündür. Gelişmekte olan ülkelerde daha çok turizmin ekonomik büyüme üzerine etkilerinin olduğu görülürken, özellikle turizmin dışındaki sektörlerin lokomotif olduğu gelişmiş ülkelerde ekonomik büyümenin turizm sektöründeki gelişmeyi beraberinde getirdiği söylenebilir. Zira ekonomik gelişmişlik düzeyi, hem bireylerin, hem devletlerin hem de yatırımcıların, bütçelerinde gelir artışı sağlayarak, bireylerin turizm talebini oluşturmalarını, devletin turizm için gerekli olan alt yapıyı kurmasını ve yatırımcıların turizm sektörüne yatırım yapmalarını sağlamaktadır.

Çalışmada Türkiye'de turizm gelirleri ve ekonomik büyüme arasındaki ilişkiyi ve bu ilişkinin yönünü göstermek amacıyla Johansen eşbütünleşme ve granger nedensellik analizi uygulanmıştır. Türkiye'de 2003-2014 yılı çeyrek verileri incelendiğinde, turizm gelirleri ve ekonomik büyüme arasında uzun dönemli bir ilişkinin olduğu ve ekonomik büyümenin turizmi tetiklediği sonucuna ulaşılmıştır. T.C. Kalkınma Bakanlığı 2014 yılı programında Türkiye'de sektörlerin GSYİH içerisindeki payları olarak inşaat sektörünün $\% 6$, sanayi sektörünün $\% 22,3$, tarım sektörünün $\% 9$ iken turizm sektörünün $\% 4,2$ 'lik paya sahip olması bu durumun göstergesi olarak ifade edilebilir. Bu oranın yükselmesi için ise önce ekonomik büyüme sağlanmalı ve sağlanan bu büyüme sayesinde devletin son dönem turizm talebini geliştirmeye yönelik harcama ve yatırımlarda bulunması gerekmektedir.

Türkiye ekonomisi son on yılda önemli bir büyüme kaydetmiştir. Bu büyümenin olumlu etkileri bir çok sektöre yansıdığı turizm sektörüne de yansımıştır. Öncelikle kişi başına düşen milli gelirin artması ile iç turizm talebi canlanmıştır. Bunu takiben turizm alt ve üst yapı yatırımlarında önemli bir artış sağlanmıştır ve yapılan bu yatırımlar sayesinde Türkiye bugün yeni, kaliteli ve lüks konaklama tesislerine sahip olmuştur. Bu tesislerin 
yapılması Türkiye'yi turistik açıdan daha da çekici hale getirmiştir ve turist sayısı ve turizm gelirlerinin artmasını beraberinde getirmiştir. Bu dönemde ayrıca turizmin farklı türlere, bölgelere ve mevsimlere yayılması anlamında önemli gelişmeler kaydedilmiş ve turizmin çeşitlendirilmesi yönünde önemli adımlar atılmıştır. Bunun yanı sıra, turizm sektöründe önemli bir istihdam artışı sağlanmış ve sektörde istihdam ile ilgili önemli düzenlemelere gidilmiştir.

Türkiye turizminde son y1llarda kaydedilen bu önemli gelişmenin önümüzdeki dönemlerde de artarak devam edebilmesi için ekonomi, turizm ve maliye yönetimi açısından ortaya atılabilecek önerileri sıralamak gerekirse, öncelikli olarak turizme ülke ekonomisine ve istihdamına önemli katkılar sağlayan öncelikli bir sektör olarak yaklaşılmasına devam edilmelidir. Ancak, turizmi ülke ekonomisini tetikleyen bir güç olarak kabul etmek çok doğru bir yaklaşım olmayacaktır. Zira turizm sektörü riskli ve kırılgan bir sektör olarak kabul edilmektedir. Bu nedenle, sanayi ve diğer üretim sektörlerinin büyümesine ve ekonomiyi tetiklemesine yönelik politikalar geliştirilmelidir. Teknoloji alanındaki yatırımlara ve ar-ge çalışmalarına önem verilmeli ülkenin her alanda kendi teknolojisini üretebilen bir konuma ulaşması hedeflenmelidir.

Mali anlamda ise devletin turizme yönelik birçok yatırım, istihdam ve vergi teşvikleri bulunmaktadır. Turizm sektörünün geliştirilmesine yönelik teşviklerin artarak devam etmesi sektörün büyümesi açısından gereklidir. Ayrıca devletin teşvikler dışında harcamalarına da ağırlık vermesi gerekmektedir. Bu amaçla son dönem turizm talebini geliştirmeye yönelik altyapı, üst yapı, ulaşım, sağlık, spor, kongre turizmi gibi öne çıkan sektörlere yönelik harcamalarını artırması, yurtiçi ve yurtdışında etkin pazarlama politikalarının yürütülmesi, sektörün kalkınması için önemlidir.

Turizm ile ilgili dikkate alınabilecek en önemli öneri ise kişi başına düşen turist harcamalarının yükseltilerek turist sayısında elde edilen başarının turizm gelirlerinde de sağlanmasını gerçekleştirecek politikaların izlenmesidir. Bunun için, hizmet kalitesinin ve imajın yükseltilerek fiyatların yükseltilmesi yönünde çaba sarf edilmelidir. Turizmin ekonomik etkilerinin tüm bölgelere yayılması konusunda teşvikler sağlanmalı, yeni yatırımların çevreyi tahrip etmeyecek şekilde sürdürülebilir bir anlayışla planlanmasına özen gösterilmelidir.

\section{Kaynakça}

Aktaş, C. (2005), “Türkiye'nin Turizm Gelirini Etkileyen Değişkenler İçin En Uygun Regresyon Denkleminin Belirlenmesi”, Doğuş Üniversitesi Dergisi, 6(2), 163-174.

Aslan, A. (2008), “Türkiye'de Ekonomik Büyüme ve Turizm İlişkisi Üzerine Ekonometrik Analiz”, Erciyes Üniversitesi SBE Dergisi, 24, 1-11. 
Bahar, O. \& B. Kurtuluş (2010), “Gelişmekte Olan Ülkelerde Turizm-Ekonomik Büyüme İlişkisi: Dinamik Panel Veri Analizi”, Anatolia: Turizm Araştırmaları Dergisi, 21(2), Güz, 255265.

Balaguer, J. \& C. Manuel (2002), "Tourism as a Long-run Economic Growth Factor: the Spanish Case", Applied Economics, 34(7), 877-884.

Belloumi, M. (2010), “The Relationship between Tourism Receipts, Real Effective Exchange Rate and Economic Growth in Tunisia", International Journal of TourismResearch, 12, 550 560.

Chen, C. \& C. Song Zan (2009), "Tourism Expansion, Tourism Uncertainty and Economic Growth: New Evidence from Taiwan and Korea", Tourism Management, 30, 812-818.

Değer, M.K. (2006), “Turizme ve İhracata Dayalı Büyüme: 1980-2005 Türkiye Deneyimi”, İktisadi ve İdari Bilimler Dergisi, 20(2), Eylül, 67-86.

Engle, R.F. \& C.W.J. Granger (1987),” Co-integration and Error Correction: Representation, Estimation, and Testing", Econometrica, 55(2), 251-276.

Ertuğrul, H.M. \& F. Mangir (2013), “The Tourism Led Growth Hypothesis: Empirical Evidence from Turkey", Current Issues in Tourism, <http://dx.doi.org/10.1080/13683500.2013.868409>, 28.08.2014.

Fayıssa, B. \& C. Nsiah \& B. Tadasse (2008), "Impact of Tourism on Economic Growthand Development in Africa", Tourism Economics, 14(4), 807-818.

Granger, C.W.J. (1988), "Causality, Cointegration and Control”, Journal of Economic Dynamics and Control, 12, 551-559.

Gunduz, L. \& A. Hatemi (2005), “Is The Tourism Led Growth Hypothesis Valid For Turkey?”, Applied Economics Letters, 12, 499-504.

Jackman, M. (2012), "Revisiting the Tourism-Led Growth Hypothesis for Barbados: A Disaggregated Market Approach", Regional and Sectoral Economic Studies, 12(2), 1526.

Johansen, S. \& K. Juselius (1990), "Maximum Likelihood Estimation and Inference on Cointegration With Application to the Demand for Money", Oxford Bulletin of Economics and Statistics, 52, 169-209.

Johansen, S. (1988), "Statistical Analysis of Cointegration Vectors", Journal of Economic Dynamics and Control, 12, 231-254.

Johansen, S. (1991), "Estimation and Hypothesis Testing of Cointegration Vectors in Gaussian Vector Autoregressive Models", Econometrica, 59, 1551-1580.

Karataş, M. \& S. Babür (2013), “Gelişen Dünya'da Turizm Sektörünün Yeri”, KMÜ Sosyal ve Ekonomik Araştırmalar Dergisi, 15(25), 15-24.

Kara, O. \& İ. Çömlekçi \& V. Kaya (2012), “Turizm Gelirlerinin Çeşitli Makro Ekonomik Göstergeler ile İlişkisi: Türkiye Örneği (1992 - 2011)”, Ekonomik ve Sosyal Arastırmalar Dergisi, Bahar, Y11: 8, 8(1), 75-100.

Katircioglu, S.T. (2009), "Revisiting The Tourism-Led-Growth Hypothesis For Turkey Using the Bounds Test and Johansen Approach For Cointegration", Tourism Management, 30, 17 20. 
Keating, J.W. (1990), “Identifying VAR Models Under Rational Expectations”, Journal of Monetary Economics, 25.

Kızılgöl, Ö. \& E. Erbaykal (2008), “Türkiye'de Turizm Gelirleri İle Ekonomik Büyüme İlişkisi: Bir Nedensellik Analizi”, Süleyman Demirel Üniversitesi Íktisadi ve İdari Bilimler Fakültesi Dergisi, 13(2), 351-360.

Kima, H.J. \& C. Ming-Hsiang \& S.J. Soo Cheong (2006), “Tourism Expansion and Economic Development: The Case of Taiwan”, Tourism Management, 27, 925-933.

Koncul, N. (2007), "Public Expenditure and Public Policies for Tourism", Zagreb International Review of Economics \& Business, 10(2), 87-93.

Kültür ve Turizm Bakanlığı (2012), "Türkiye'de Turizm Sektörüne Tanınan Teşvik ve Destekler", Kültür ve Turizm Bakanlı̆̆l Yatırım ve Issletmeler Genel Müdürlügü Raporu.

Lee, C.G. (2008), "Tourism and Economic Growth: The Case of Singapore”, Regionaland Sectoral Economic Studies, Vol. 8-1.

Maddala, G.S. (1989), Introduction to Econometrics, New York, Macmillan Publishing Company.

Marin, D. (1992), “Is The Export-Led Hypothesis Valid For Industrialized Countries?”, Review of Economics and Statistics, 74, 678-688.

Martín, J.L. \& N.L. Eugenio \& R.S. Morales (2004), "Tourism and Economic Growth in Latin American Countries: A Panel Data Approach”, Nota Di Lavoro, 26.

Metodijeski, D. \& T. Zoran (2014), "Tourism Policy of Balkan Countries: Review of National Tourism Development Strategies", UTMS Journal of Economics, 5(2), 231-239.

Narayan, P. \& S.N. Kumar \& B. Arti Prasad \& C. Prasad (2010), "Tourism and Economic Growth: A Panel Data Analysis for Pacific Island Countries", Tourism Economics, 16(1), 169183.

Nordin, S., (2003), "Tourism Clustering \& Innovation: Paths to Economic Growth and Development”, ETOUR European Tourism Research Institute, Utredningsserien Analysoch Statistik U 2003: 14.

Oh, C. (2005), "The Contribution of Tourism Development to Economic Growth in the Korean Economy", Tourism Management, 26, 39-44.

Özdemir, A.R. \& O. Öksüzler (2006), “Türkiye'de Turizm Bir Ekonomik Büyüme Aracı Olabilir mi? Bir Granger Nedensellik Analizi”, Balıkesir Üniversitesi Sosyal Bilimler Dergisi, 9(16), Aral1k, 107-126.

Sequeira, T. \& C.C. Neves (2005), "International Tourism and Economic Growth: a Panel Data Approach”, Nota diLavoro, Fondazione Eni Enrico Mattei, No. 141.

T.C. Kalkınma Bakanlığı (2013), 2014 Yılı Programı.

Tezcan, K. \& E. Karadeniz \& S.Y. Kandır \& Y.B. Önal (2008), “Türk Turizm Sektörünün Gelişimi Açısından Uygulanan Vergi Politikalarının Değerlendirilmesi”, IV. Lisansüstü Turizm Ögrencileri Araştırma Kongresi, 827-851.

Yavuz, N.Ç. (2006), “Türkiye’de Turizm Gelirlerinin Ekonomik Büyümeye Etkisinin Testi: Yapısal Kırılma Ve Nedensellik Analizi”, Doğuş Üniversitesi Dergisi, 7(2), 162-171. 
Balıkçığlu, E. \& K. Oktay (2015), “Türkiye'de Turizm Gelirleri ve Ekonomik Büyüme İlişkisinin Kamu Politikaları Doğrultusunda Değerlendirilmesi”, Sosyoekonomi, Vol. 23(25), 113-125. 